\title{
Sliding Mode Control of A DC Distributed Solar Microgrid
}

\author{
Dan Shen, Afshin Izadian, Senior Member, IEEE \\ Energy Systems and Power Electronics Laboratory \\ Purdue School of Engineering and Technology, Indianapolis 46202, USA \\ aizadian@iupui.edu
}

\begin{abstract}
This paper proposes a standalone distributed photovoltaic system which includes two independently controlled solar power sources, a battery storage and a resistive load. Each of the PV panels consist of cascaded DC-DC boost converters controlled through two independent sliding mode controllers. The design and simulation of the supervisory controller are also discussed. First, maximum power point tracking (MPPT) control strategy is introduced to maximize the simultaneous energy harvesting from both renewable sources. Then, according to the power generation available at each renewable source and the state of charge in the battery, four contingencies will be considered in the supervisory controller. Moreover, power converters interfacing the source and common DC bus will be controlled as voltage sources under a PI-sliding mode controller. Numerical simulations demonstrate accurate operation of the supervisory controller and functionality of the MPPT algorithm in each operating condition.
\end{abstract}

\section{INTRODUCTION}

With the fossil fuel exhausting and environmental problems, renewable energy is developing rapidly. Compared with other renewables, photovoltaic have been established as one proven future source of energy. This is because of their environmentally-friendly, safe and cost-effective characteristics. However, there are some difficulties associated with PV combined utilization, e.g. intermittency of solar and instability of the grid. For this purpose, more advanced and reliable network of multiple renewable power systems with storage units have been proposed [1], [2], [3]. For instance, small-scale standalone combination of renewable micro-grids has been found effective in some specific areas. Simultaneous intermittency of solar can be compensated by utilizing of energy storage devices.

Recent advances in DC distribution systems have shown several advantages with respect to AC systems. First, DC system can provide higher quality power with lower harmonics [4], [5]. Secondly, a significant superiority of DC topology is the fact that the power handling can be completely uninterrupted by having switched-mode power converters featuring the current limit [6], allowing the final aggregation of standalone energy sources to the main DC grid [7], [8]. In addition, the connection of PV system to DC bus is implemented through two methods, such as connecting series PV panels to the central power converter and utilizing one power converter per solar module, or micro-converters. Obviously, the latter case is more popular due to its higher flexibility of system layout, lower sensitivity to system disturbance, better protection of PV sources, and safer installation and maintenance. However, installation of one converter per solar panel can have difficulties for achieving the desired constant output voltage level when the climate changes. For this purpose, it is necessary to have two stages of converters to realize the MPPT and output voltage control at the same time.

In this paper, we propose the configuration of two cascaded boost converters which run MPPT at the first stage and do the terminal voltage control at the second stage. In addition, a battery is directly connected to the DC bus and is controlled through the bus voltage variation. The power converters interfacing the PV can inject the power as a voltage source. Supervisory controller determines the source type according to the availability and rating of the power. As the DC bus voltage floats, the battery can be charged or discharged. A designated voltage source will be controlled to charge the battery at the desired rate. This new distributed system improves the stability and reliability of power supply [9], [10], [11]. Maximum power point tracking is continuously operated to maximize the power from two solar systems. A sliding mode control approach [12],[13] based on loss free resistor (LFR) concept [14] is utilized on the solar power sources to accomplish MPPT[15],[16].

This paper is organized as follows, the proposed distributed energy generation system is given in section II. Section III describes the Extremum Seeking Control (ESC) MPPT for solar system by utilizing the sliding mode theory through a cascaded boost converters working as LFRs. Supervisory control strategy is discussed in section IV. Section V represents some associated simulation results of the proposed system. Finally, the conclusions of the paper are summarized in section VI.

\section{DISTRIBUTED ENERGY GENERATION UNIT}

Figure 1 depicts the proposed topology of the combined power sources consisting of two PV panels, battery with cascaded boost DC-DC converters interfaces a load. The two first stage converters are controlled by MPPT controllers based on sliding mode control (SMC) theory. Each of them receives the PV voltage and current from solar and runs a maximum-power-point tracking (MPPT) algorithm to adjust the sliding surface with the conductance $g_{l}$. The second-stage sliding mode control of boost converter will be regulated by a local PI controller to operate as a constant voltage sources (CVS) with a constant value $g_{2}$. The supervisory controller receives signals of the state of charge from battery and output power from each PV systems, and determines the next appropriate control mode under different scenarios. The two

This is the author's manuscript of the article published in final edited form as: Shen, D., \& Izadian, A. (2015). Sliding mode control of a DC distributed solar microgrid. In 2015 IEEE Power and Energy Conference at Illinois (PECI) (pp. 1-6). http://doi.org/10.1109/PECI.2015.7064929 
energy sources are connected in parallel to a common DC bus through their individual DC-DC converters [17], [18], [19].

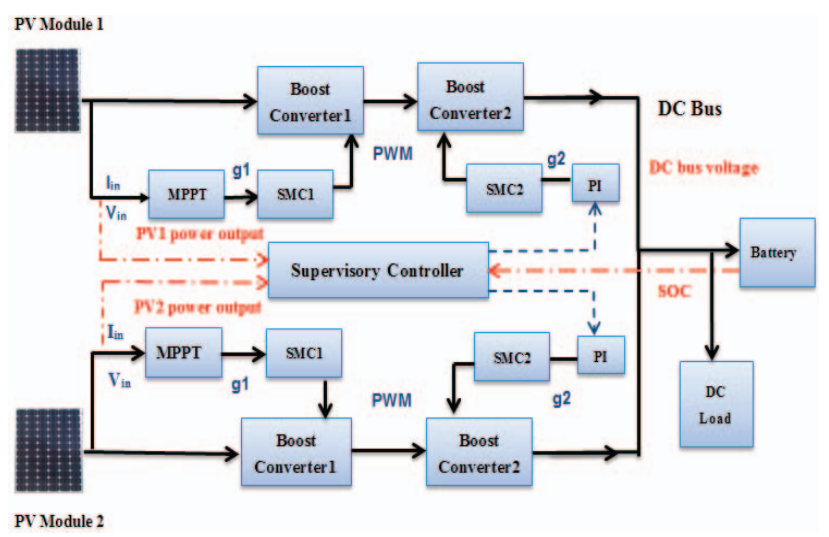

Fig. 1. Proposed distributed energy generation system.

\section{MPPT For SOLAR SYSTEM UNDER SLIDING MODE CONTROL}

A PV power system usually includes PV panels, power converters and load. The maximum power point can be captured by tuning the controller and regulating the converter. Some MPPT control methods have also been proposed for PV generation system to eliminate the probable mismatch between solar power and its ideal maximum power under different climate. In this way, tracking MPP is quite important for solar system not only to enhance the efficiency of system but also to reduce the cost of energy. In this work, we propose a two-stage method by using cascaded boost converters due to its high conversion ratios. However, the cascaded configuration has some inherent drawbacks regarding on the controller design and system dynamic stability, which can be seen with the impedance ratio criteria by R.D. Middlebrooks [20]. So this section will focus on the solar MPPT controller based on the sliding mode approach.

\section{A. PV Impedance Matching and Sliding Mode Controller}

MPPT searches the operating voltage close to the maximum power point (MPP) in various environmental conditions. As we know, the electrical circuit of power converters can be represented and analyzed by using the ideal canonical elements, such as LFR which belongs to a range of circuits named POPI (power input equals to the power output). Thus, the input port can absorb the power and then transfer it to the output without losses [21], [22]. The architecture of PV system connecting to boost-boost converter with a DC load is illustrated in Figure 2(a). The output power can be obtained by the following function of the LFR conductance $\mathrm{g}_{1}=1 / \mathrm{r}_{1}$ :

$$
\mathrm{P}_{\mathrm{o}}=\mathrm{g}_{1} \times \mathrm{V}_{\mathrm{p}}^{2} \text {. }
$$

The I-V curve of PV module and the LFR steady-state load line are also depicted in Figure 2(b). Note that the intersection of them is the working point of PV panel, so the conductance (slope of LFR load line) can be tuned to search the optimal operating point of solar system through modifying $g$ conductance value [23],[24]. The following two sliding mode control surfaces are also set to behave as switches for each boost converters:

$$
\begin{aligned}
& s_{1}(x)=g_{1} v_{p}-i_{L_{1}} \\
& s_{2}(x)=g_{2} v_{c_{1}}-i_{L_{2}}
\end{aligned}
$$

where $\mathrm{g} 1$ is conductance of PV panel, $\mathrm{v}_{\mathrm{p}}$ is output voltage of PV cell, $i_{L 1}$ is output current of the first stage, g2 is the conductance of second boost converter, $\mathrm{v}_{\mathrm{c} 1}$ is the capacitance of intermediate capacitor between converters, and $\mathrm{i}_{\mathrm{L} 2}$ is the output current of the system.

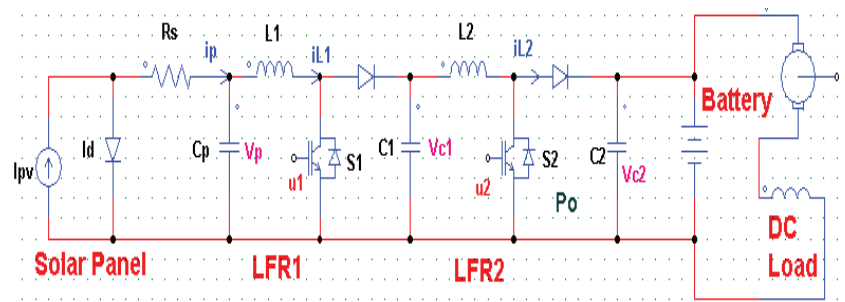

(a)

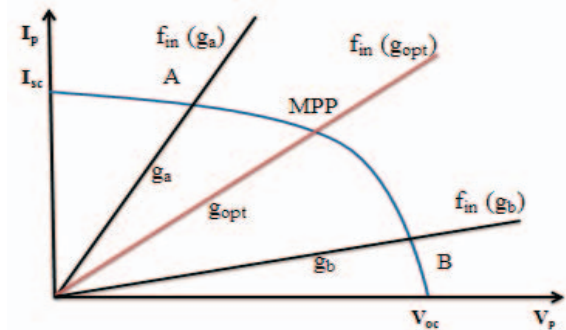

(b)

Fig. 2. (a) Schematic diagram of two cascaded boost converters based on LFRs. (b) PV panel operating points for impedance matching between the PV generator and the LFR.

\section{B. Maximum Power Point Tracking Technique}

The purpose of MPPT in PV is to obtain the best operating point that controls the PV around the MPP in spite of the temperature, insolation and load variation. There are many tracking methods applied to different types of DC-DC converters [25]-[28]. The Extremum Seeking Control (ESC) is one of the popular MPPT algorithms which can control the PV system to approach the MPP by increasing or decreasing a suitable control signal, its block diagram is shown in Figure 3. The input of the MPPT controller sets the output voltage and current of the PV panel, and is passed through a low pass filter, the power variation, $\mathrm{dP}$, is calculated as the input signal of hysteretic comparator (HC). HC can generate a binary signal which reflects whether $\mathrm{dP}$ is positive or negative. This key information will be sent to a logic circuit that can determine the next direction of maximum power point tracking control signal maintained or changed. In the last stage, the control signal of searching direction is introduced to an integrator to get the conductance g1 of first stage boost converter [23], [28].

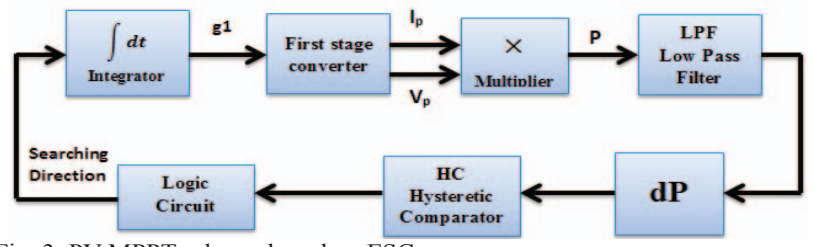

Fig. 3. PV MPPT scheme based on ESC. 
For the voltage control at the terminal of cascaded boost converters, a PI controller is established to generate g2 as the conductance value of the second LFR. So the terminal voltage will be fixed to satisfy load requirement under different weather conditions.

\section{Mathematical Modeling}

For the switched model of the cascaded boost converter, the system dynamic behavior can be described from the following four differential equations according to Figure 2(a) by using the Kirchhoff's voltage and current laws as follows:

$$
\begin{aligned}
\frac{d i_{L 1}}{d t} & =\frac{V_{p}}{L_{1}}-\frac{V_{c 1}}{L_{1}}\left(1-u_{1}\right) \\
\frac{d i_{L 2}}{d t} & =\frac{V_{C 1}}{L_{2}}-\frac{V_{d c}}{L_{2}}\left(1-u_{2}\right) \\
\frac{d V_{p}}{d t} & =\frac{i_{p}}{C_{p}}-\frac{i_{L 1}}{C_{p}} \\
\frac{d V_{c 1}}{d t} & =\frac{i_{L 1}}{C_{1}}\left(1-u_{1}\right)-\frac{i_{L 2}}{C_{1}},
\end{aligned}
$$

where $\mathrm{u}_{1}$ and $\mathrm{u}_{2}$ are control signals for the two stage boost converter respectively. When the first stage or the second stage control command equals unity, it means the switch $\mathrm{S}_{1}$ or $\mathrm{S}_{2}$ is closed; and a zero control command means switch $\mathrm{S}_{1}$ or $\mathrm{S}_{2}$ is open. All other parameters are described on Figure 6.

The two terminal sliding mode functions $\mathrm{s}_{1}(\mathrm{x})$ and $\mathrm{s}_{2}(\mathrm{x})$ is defined in (2)-(3). If the sliding surface $s(x)$ is always kept at zero such that:

$$
\begin{gathered}
s_{1}(x)=g_{1} v_{p}-i_{L_{1}}=0 \\
s_{2}(x)=g_{2} v_{c_{1}}-i_{L_{2}}=0 .
\end{gathered}
$$

To continue the SMC design, we also take the time derivative of the two terminal sliding mode surfaces along (8) (9) and obtain:

$$
\begin{aligned}
& \dot{s_{1}}(x)=g_{1} \frac{d V_{p}}{d t}+V_{p} \frac{d g_{1}}{d t}-\frac{d i_{L 1}}{d t}=0 \\
& \dot{s}_{2}(x)=g_{2} \frac{d V_{C 1}}{d t}-\frac{d i_{L 2}}{d t}=0
\end{aligned}
$$

In order to achieve the fast convergence of the sliding surfaces and drive the trajectories of the system are evolving on the switching manifolds, the control signals $\mathrm{u} 1$ and $\mathrm{u} 2$ can be represented from the full-order switched model and equations (8)-(11). Under sliding mode conditions, the control laws which describe the dynamic behavior of the system that is restricted to the two switching surfaces can be obtained as follows:

$$
\begin{gathered}
u_{1}=1-\frac{V_{d}}{V_{c 1}}-\frac{1}{V_{c 1}}\left(V_{p} L_{1}\left(\frac{m_{2}\left(m_{3} V_{c}-\varepsilon\right)}{\tau_{1}}\right)\right) \\
u_{2}=1-\frac{1}{V_{d c}}\left(V_{c 1}+\frac{g_{2} L_{2}}{C_{1}}\left(g_{2} V_{c 1}+\frac{g_{1} V_{p}}{V_{c 1}}\left(V_{p}-\frac{g_{1} L_{1}}{C_{p}}\left(i_{p}-\right.\right.\right.\right. \\
\left.\left.\left.g_{1} V_{p}\right)\right)\right)
\end{gathered}
$$

where $m_{2}$ and $m_{3}$ are constants, $\varepsilon$ is the next direction of maximum power tracking and $\tau_{1}$ is a time constant. It should be noted that the control variables $\mathrm{u}_{1}$ and $\mathrm{u}_{2}$ are PWM signals which must be bounded between minimum 0 and maximum 1 [23], i.e.:

$$
0 \leq u_{1} \leq 1 \text { and } 0 \leq u_{2} \leq 1
$$

\section{SUPERVISORY CONTROL STRATEGY}

In a DC system where multiple source converters supply the same bus, current sharing and system protection are required. Therefore, the supervisory control decides on the flow of power from local sources according to the system operating contingencies (Table I). The results is either a charge or discharge control command which makes the entire system's performance more smooth and efficient $[29,30]$. The inputs of the supervisory controller are the output power of the two solar cells and the state of charge of battery. The supervision modes are shown in Table I. The net power that the battery needs to provide or absorb, $\Delta \mathrm{P}$, is obtained as follows:

$$
\Delta P=P_{P V 1}+P_{P V 2}-P_{\text {Load }},
$$

where $P_{P V_{1}}$ is the output power of the first PV system, $P_{P V_{2}}$ is the output power of the second PV system, and $P_{\text {Load }}$ is the power demand from the DC machine.

The supervision mode is shown in Table I can be categorized like follows:

If $\Delta P$ is not less than zero and SOC is between 0 and $95 \%$, then the net power will be utilized to feeding load and charging battery at the same time. When $\Delta P$ is not less than zero and SOC is higher than $95 \%$, then the load will be satisfied and the battery is in the floating charge state, note that the surplus power should be through a dummy load. When $\Delta P$ is less than zero and SOC is higher than $40 \%$, then the available energy and the battery both satisfy the load power demand. In the worst case scenario, $\Delta P$ is less than zero and SOC is also lower than $40 \%$, the load can be disconnected and the whole generated power is applied to charge the battery.

TABLE I.

THE SUPERVISION MODE OF DISTRIBUTED ENERGY GENERATION SYSTEM

\begin{tabular}{|c|c|c|}
\hline Mode & Condition & Control Effect \\
\hline 1 & $\begin{array}{c}\Delta \mathrm{P} \geqslant 0,0 \leqslant \mathrm{SOC} \leqslant \\
95 \%\end{array}$ & Feeding Load and charge Battery \\
\hline 2 & $\Delta \mathrm{P} \geqslant 0, \mathrm{SOC}>95 \%$ & $\begin{array}{c}\text { Feeding Load and battery } \\
\text { (Surplus power through a dummy } \\
\text { load) }\end{array}$ \\
\hline 3 & $\Delta \mathrm{P} \leqslant 0$, SOC $<40 \%$ & Charge battery and off load \\
\hline 4 & $\Delta \mathrm{P} \leqslant 0$, SOC $>40 \%$ & $\begin{array}{c}\text { Feeding load and battery discharge } \\
\text { to the load }\end{array}$ \\
\hline
\end{tabular}

\section{NumERICAL SIMULATIONS}

In order to verify the previous applied theories, the whole system is simulated in Matlab/Simulink. The validity of the proposed system has been checked in the following figures, the sample time of the simulations has been set to $1 \mathrm{e}-6$. The waveforms for the cascaded converters behaving as LFRs supplied from PV source under MPPT by applying sliding mode control depicted in Figure 4. Figure 4(a) shows the MPP tracking profile with an irradiance change from $1000 \mathrm{~W} / \mathrm{m}^{2}$ to $800 \mathrm{~W} / \mathrm{m}^{2}$ and Figure 4(b) illustrates the waveforms of PV power, voltage and current and first stage voltage during an irradiance change from $800 \mathrm{~W} / \mathrm{m}^{2}$ to $600 \mathrm{~W} / \mathrm{m}^{2}$. 


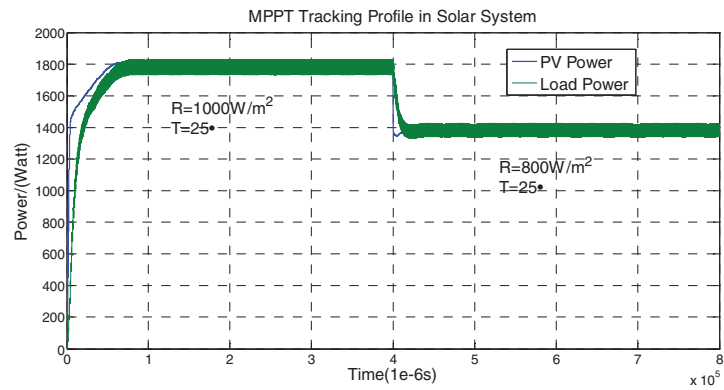

(a)

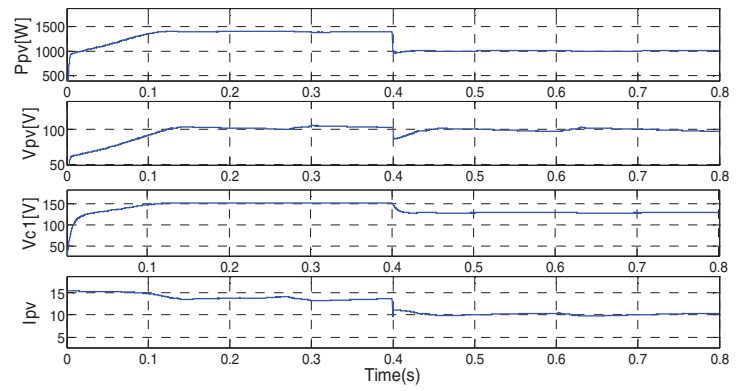

(b)

Fig. 4. Waveforms for the cascaded converters behaving as LFRs supplied from PV source under MPPT by applying sliding mode control at fixed temperature $25^{\circ} \mathrm{C}$ (a) MPP tracking profile (b) PV power, voltage, current and first stage voltage.

Then Figures 5 and 6 represent the system responses under a step change of the load DC voltage from $240 \mathrm{~V}$ to $380 \mathrm{~V}$ and $380 \mathrm{~V}$ to $240 \mathrm{~V}$ to show the feasibility of the control system. It can be observed that increasing or decreasing the output voltage will not affect to capture the maximum power of the solar panel in the proposed system.

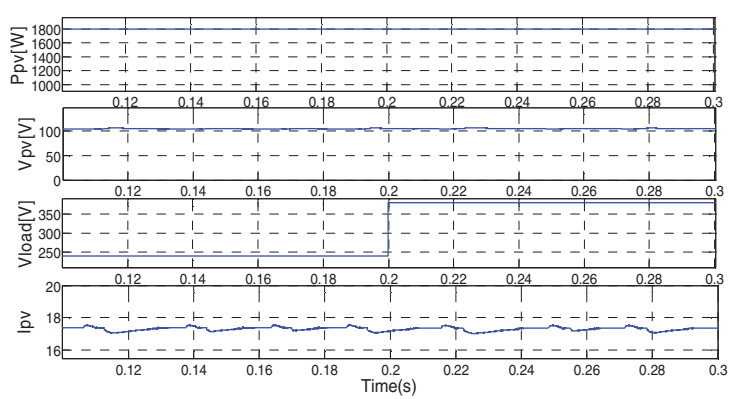

Fig. 5. Waveforms of the PV power, PV voltage and current during the load voltage changes from $240 \mathrm{~V}$ to $380 \mathrm{~V}$.

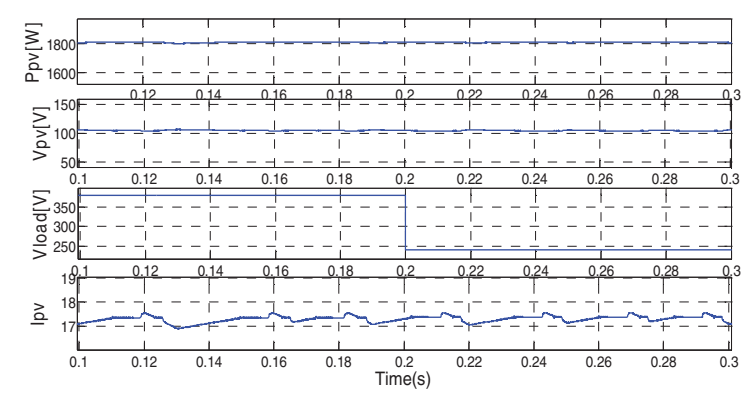

Fig. 6. Waveforms of the PV power, PV voltage and current during the load voltage changes from $380 \mathrm{~V}$ to $240 \mathrm{~V}$.
Mode 1 to mode 4 of the supervisory control effect (also listed in Table I) are demonstrated in Figures 7-9 respectively. Figure 7 mainly depicts the cases of mode 1 and mode 4, where a 900Ah battery feeds the load nearly for about 90 hours without charging at starting SOC of the $50 \%$ and the output voltage of the system should also be regulated around $260 \mathrm{~V}$. Figure 7(a) illustrates the MPP tracking effects of the two solar panels and the response of the battery power with a DC load power change from $2.5 \mathrm{~kW}$ to $3.5 \mathrm{~kW}$ to $2.5 \mathrm{~kW}$ during the irradiance change from $800 \mathrm{~W} / \mathrm{m}^{2}$ to $1000 \mathrm{~W} / \mathrm{m}^{2}$ of $\mathrm{PV}$ and $700 \mathrm{~W} / \mathrm{m}^{2}$ to $900 \mathrm{~W} / \mathrm{m}^{2}$ of $\mathrm{PV}_{2}$. Figure $7(\mathrm{~b})$ shows the MPP tracking effects of the two solar panels and the response of the battery power with the same DC load power change during the irradiance change from $1000 \mathrm{~W} / \mathrm{m}^{2}$ to $600 \mathrm{~W} / \mathrm{m}^{2}$ of $\mathrm{PV} \mathrm{V}_{1}$ and $900 \mathrm{~W} / \mathrm{m}^{2}$ to $700 \mathrm{~W} / \mathrm{m}^{2}$ of $\mathrm{PV}_{2}$. Figure $7(\mathrm{c})$ depicts the same effects with the same load power change during the irradiance change from $1000 \mathrm{~W} / \mathrm{m}^{2}$ to $600 \mathrm{~W} / \mathrm{m}^{2}$ of $\mathrm{PV}_{1}$ and $700 \mathrm{~W} / \mathrm{m}^{2}$ to $900 \mathrm{~W} / \mathrm{m}^{2}$ of $\mathrm{PV}_{2}$. The operation of controller is verified in Figures 7a-c under conditions that both PV powers follow the same direction or oppose the direction. The DC micro-grid is capable of charging and discharging the battery at the required power rate automatically while capturing the maximum power from two solar panels under variation of irradiance.
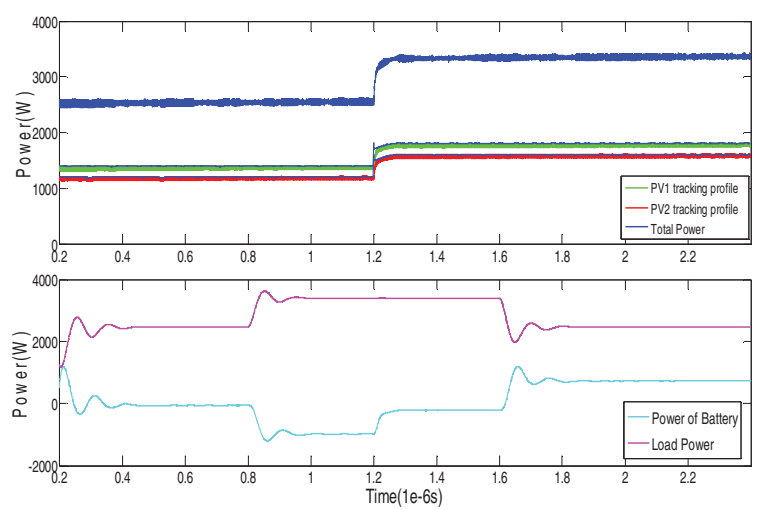

(a)
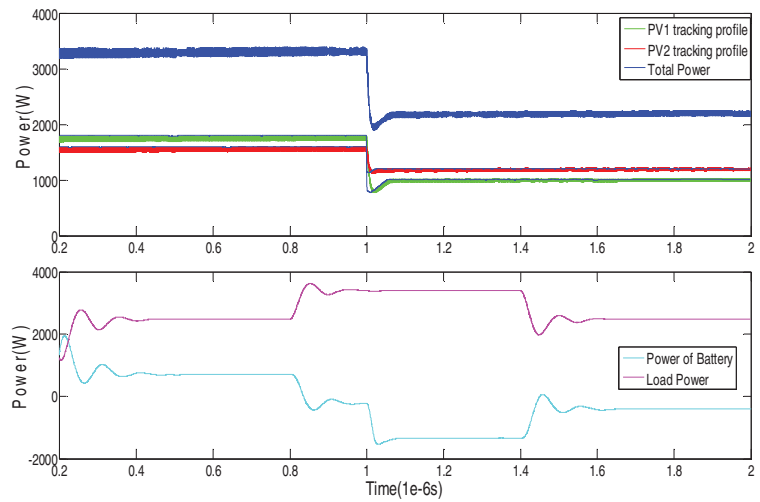

(b) 


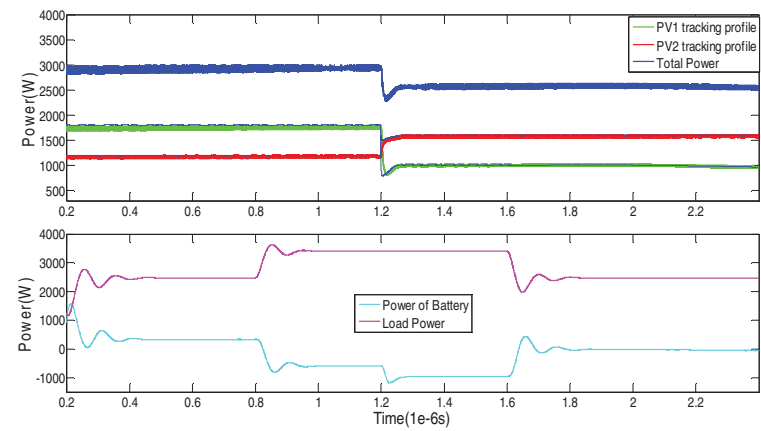

(c)

Fig. 7. PV MPPT Profile and response of battery power during step change in the load power from $2.5 \mathrm{~kW}$ to $3.5 \mathrm{~kW}$ to $2.5 \mathrm{~kW}$. (a) Irradiance varying from $800 \mathrm{~W} / \mathrm{m} 2$ to $1000 \mathrm{~W} / \mathrm{m} 2$ of $\mathrm{PV} 1$ and $700 \mathrm{~W} / \mathrm{m} 2$ to $900 \mathrm{~W} / \mathrm{m} 2$ of $\mathrm{PV} 2$. (b) $1000 \mathrm{~W} / \mathrm{m} 2$ to $600 \mathrm{~W} / \mathrm{m} 2$ of PV1 and $900 \mathrm{~W} / \mathrm{m} 2$ to $700 \mathrm{~W} / \mathrm{m} 2$ of PV2. (c) $1000 \mathrm{~W} / \mathrm{m} 2$ to $600 \mathrm{~W} / \mathrm{m} 2$ of PV1 and $700 \mathrm{~W} / \mathrm{m} 2$ to $900 \mathrm{~W} / \mathrm{m} 2$ of PV2.

Figure 8 shows the mode 2 of the distributed system. In this case $\Delta \mathrm{P}$ is equal to or larger than zero and $\mathrm{SOC}>95 \%$, it is necessary to set the terminal voltage around $270 \mathrm{~V}$ that charges the battery and maintain the capacity. This can also compensate for the self-discharge of the battery. A dummy load is also invoked to consume the surplus energy. Both power controls can be accomplished by limiting the injection of current to the battery and the dummy load based on the DC load requirement.

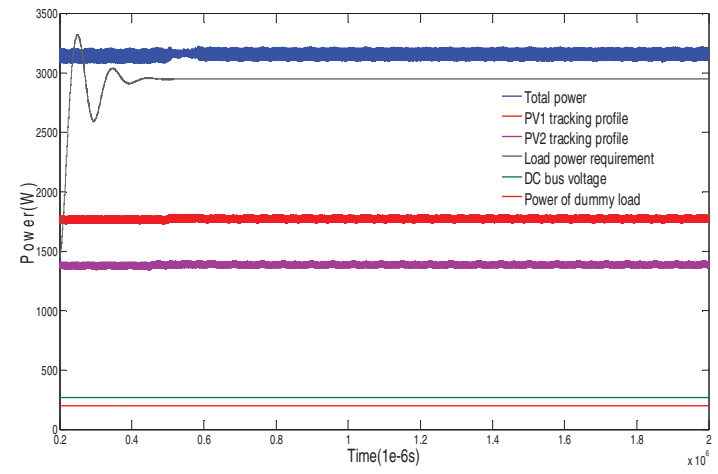

Fig. 8. Mode 2 of the supervisory control strategy

Figure 9 illustrates mode 3 which is $\Delta \mathrm{P}$ is not larger than zero and SOC lower than $40 \%$. Therefore, the load should be off and the total power captured from two PV sources is used to charge the battery without satisfying $2.5 \mathrm{~kW}$ DC load power.
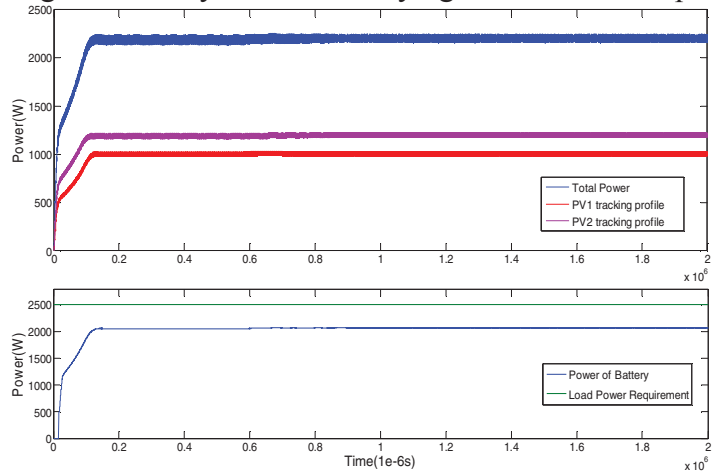

Fig. 9. Mode 3 of the supervisory control strategy

\section{CONCLUSION}

This work was focused on the modeling of distributed solar micro-grid and MPPT method based on sliding mode control theory. Models of two PV panels, their individual MPPT controllers and voltage controllers were built in Matlab/Simulink. The cascade DC-DC boost converters were utilized with high voltage conversion ratios. The cascade connection can be effectively controlled by a sliding mode structure applying a loss free resistor, therefore a relationship between the PV voltage and inductor current in boost converter can be established. The full-order switched model of the cascaded circuit has also been established and analyzed by using the Kirchhoff's voltage and current laws. The two sliding mode surfaces and control variables are obtained through a mathematical modeling of circuit and imposing the concept of LFRs. A supervisory control strategy which is resulted in 4 contingencies was proposed to generate the maximum power from two renewable energy sources while connected to a common DC bus. Simulation results demonstrated an accurate operation and applicability of the proposed method.

\section{REFERENCES}

[1] A. M. Gee, F. V. Robinson, and R. W. Dunn, "Analysis of battery lifetime extension in a small-scale wind-energy system using supercapacitors," 2013.

[2] A. Barchowsky, J. P. Parvin, G. F. Reed, M. J. Korytowski, and B. M. Grainger, "A comparative study of MPPT methods for distributed photovoltaic generation," in Innovative Smart Grid Technologies , IEEE PES, 2012, pp. 1-7.

[3] Shen D, Izadian A. Modeling and Control of A Combined Wind-Solar Microgrid, [C]//Industrial Electronics Society, IECON 2014-40th Annual Conference of the IEEE. 2014.

[4] A. Sannino, G. Postiglione, and M. H. J. Bollen, "Feasibility of a DC network for commercial facilities," IEEE Transactions on Industry Applications, vol. 39, no. 5, pp. 1499-1507, Sep. 2003.

[5] D. Nilsson, "DC distribution systems," Ph.D. dissertation, Chalmers University of Technology, Sweden, 2005.

[6] C. $\mathrm{Xu}$ and $\mathrm{K}$. Cheng, "A survey of distributed power system - AC versus DC distributed power system," in $4^{\text {th }}$ International Conference on Power Electronics Systems and Applications (PESA), Jun. 2011, pp. 1-12.

[7] B. Fahimi, A. Kwasinski, A. Davoudi, R. S. Balog, and M. Kiani, "Powering a more electrified planet," IEEE power and energy magazine,no. 2, pp. 54-64, Aug. 2011.

[8] Y.-C. Chang, C.-L. Kuo, K.-H. Sun, and T.-C. Li, "Development and operational control of two-string maximum power point trackers in DC distribution systems," IEEE Transactions on Power Electronics, vol. 28, no. 4, pp. 1852-1861, Apr. 2013.

[9] M. Cirstea and A. Parera-Ruiz, "An FPGA controller for a combined solar/wind power system," in Optimization of Electrical and Electronic Equipment (OPTIM), 2010 12th International Conference on, 2010, pp. 1103-1108. 
[10] R. G. Wandhare and V. Agarwal, "A control strategy to reduce the effect of intermittent solar radiation and wind velocity in the hybrid photovoltaic/wind SCIG system without losing MPPT," in Photovoltaic Specialists Conference (PVSC), 2012 38th IEEE, 2012, pp. 001399-001404.

[11] F. Nejabatkhah, S. Danyali, S. H. Hosseini, M. Sabahi, and S. M. Niapour, "Modeling and Control of a New Three-Input DC-DC Boost Converter for Hybrid PV/FC/Battery Power System," Power Electronics, IEEE Transactions on, vol. 27, pp. 2309-2324, 2012.

[12] V. I. Utkin, Sliding modes and their application in variable structure systems. MIR Publishers, 1978.

[13] P. Mattavelli, L. Rossetto, G. Spiazzi, and P. Tenti, "General-purpose sliding-mode controller for DC/DC converter applications," in 24th Annual IEEE Power Electronics Specialists Conference, (PESC), Jun. 1993, pp. $609-615$.

[14] R. Erickson and D. Maksimovic, Fundamentals of power electronics. Springer Science and Business Media Inc, 2001.

[15] W. Xiao and W. G. Dunford, "A modified adaptive hill climbing MPPT method for photovoltaic power systems," in Power Electronics Specialists Conference, 2004. PESC 04. 2004 IEEE 35th Annual, 2004, pp. 1957-1963.

[16] B. Subudhi and R. Pradhan, "A comparative study on maximum power point tracking techniques for photovoltaic power systems," 2013.

[17] A. Traca de Almeida, A. Martins, H. Jesus, and J. Climaco, "Source reliability in a combined wind-solar-hydro system," Power Apparatus and Systems, IEEE Transactions on, pp. 1515-1520, 1983.

[18] C. Liu, K. Chau, and X. Zhang, "An efficient wind-photovoltaic hybrid generation system using doubly excited permanent-magnet brushless machine," Industrial Electronics, IEEE Transactions on, vol. 57, pp. 831-839, 2010

[19] W.-M. Lin,C.-M.Hong, and C.-H. Chen, "Neural-network-based MPPT control of a stand-alone hybrid power generation system," Power Electronics, IEEE Transactions on, vol. 26, pp. 3571-3581, 2011.

[20] Middlebrook R D. Input filter considerations in design and application of switching regulators[J]. in IEEE Industry Applications Society annual Meeting, 1976, pp. 366-382.
[21] S. Singer and R. Erickson, "Canonical modeling of power processing circuits based on the POPI concept," IEEE Transactions on Power Electronics, vol. 7, no. 1, pp. 37-34, Jan. 1992.

[22] S. Singer, "Realization of loss-free resistive elements," IEEE Transactions on Circuits and Systems, vol. 37, no. 1, pp. 54-60, Jan. 1990.

[23] R.Haroum, El Aroudi, A.Cid-Pastor, G. Garcia, C.Olalla, L.Martinez-Salamero, "Impedance Matching in Photovoltaic Systems Using Cascaded Boost Converters and Sliding-Mode Control," Power Electronics, IEEE Transactions on, 2014.

[24] L. Martinez-Salamero, "Synthesis of canonical elements for power processing," in 6th International Multi-Conference on Systems, Signals and Devices, Mar. 2009, pp. 1-6.

[25] T. Noguchi, S. Togashi, and R. Nakamoto, "Short-current pulse-based maximum-power-point tracking method for multiple photovoltaic-and converter module system," IEEE Transactions on Industrial Electronics,vol. 49, no. 1, pp. 217-223, Feb. 2002.

[26] N. Femia, G. Petrone, G. Spagnuolo, and M. Vitelli, "Optimization of perturb and observe maximum power point tracking method," IEEE Transactions on Power Electronics, vol. 20, no. 4, pp. 963-973, Jul. 2005.

[27] M. A.G. de Brito, L. Galotto, L. P. Sampaio, G. de Azevedo e Melo, and C. A. Canesin, "Evaluation of the main MPPT techniques for photovoltaic applications," IEEE Transactions on Industrial Electronics, vol.60, no.3,pp.1156-1167, Mar. 2013.

[28] R. Leyva, C. Alonso, I. Queinnec, A. Cid-Pastor, D. Lagrange, and L. Martinez-Salamero, "MPPT of photovoltaic systems using extremumseeking control," IEEE Transactions on Aerospace and Electronic Systems, vol. 42, no. 1, pp. 249-258, Jan. 2006.

[29] Shen D, Izadian A, Liao P. A hybrid wind-solar-storage energy generation system configuration and control[C]//Energy Conversion Congress and Exposition (ECCE), 2014 IEEE. IEEE, 2014: 436-442.

[30] W. Qi, J. Liu, X. Chen, and P. D. Christofides, "Supervisory predictive control of standalone wind/solar energy generation systems," Control Systems Technology, IEEE Transactions on, vol. 19, pp. 199-207, 2011. 